\title{
Contemporary Recommendations for Primary Care Management of Patients with HIV Infection
}

\author{
William N. Hannah and Jason F. Okulicz* \\ Department of Medicine, Division of Internal Medicine and Infectious Disease Service, San Antonio Military Medical Center, San Antonio TX, USA
}

\begin{abstract}
The morbidity and mortality associated with HIV infection has decreased significantly in the current era of antiretroviral therapy, with HIV-infected individuals now anticipating a normal life expectancy in developed countries. HIV has transformed from a disease of certain death into a chronic condition that can be managed medically. Reflecting this change, the Infectious Disease Society of America (IDSA) recently released an update on the management of HIV with a new emphasis on primary care and enhanced screening for comorbid conditions. For individuals with well-controlled HIV infection, the frequency of viral load and CD4 cell count monitoringcan is reduced from every 3-4 months to every 6-12 months. Increased attention is devoted to immunizations with new recommendations for HPV vaccination in males and an updated pneumococcal vaccination schedule. There is also an enhanced section on sexually transmitted diseases including annual screening for trichomoniasisin women, yearly screening for gonorrhea and chlamydia in at risk individuals, and anal cytologic screening in certain risk groups. This article reviews the 2013IDSA guidelines, highlights significant changes from prior IDSA guidelines, and contrasts these recommendations with other United States screening guidelines.
\end{abstract}

Abbreviations: IDSA: Infectious Disease Society of America; HbA1C: Hemoglobin A1C; NCEP: National Cholesterol Education Program; IM: Intramuscular; HPV: Human Papilloma Virus; MSM: Men who have Sex with Men; HIV: Human Immunodeficiency Virus; STD: Sexually Transmitted Disease

In the current era of antiretroviral therapy (ART), HIV-infected individuals can anticipate a full and meaningful lifespan. However, patients on effective ART are at increased risk for common medical conditions such as diabetes, osteoporosis, elevated cholesterol, and cardiovascular disease. These can occur secondary to a combination of factors, including chronic HIV infection, adverse effects of ART, and traditional lifestyle risk factors. With this in mind, physicians treatingpatients with HIV infection need to address primary prevention of these common medical conditions in addition toHIV-specific treatment goals. This attention to preventive medicine is reflected in the recently published 2013 Infectious Disease Society of America(IDSA) update on primary care management of patients infected with HIV [1]. These updated guidelines will be highlighted herein, with attention to specific recommendations differing from the prior 2009 IDSA guidelines (Table 1) [2]. In addition, comparisons will also be made toappropriate United States primary care screening guidelines.

With the focus of HIV management shifting to primary prevention and long-term disease management, the updated 2013 HIV primary care guidelines recommend significant changes to the schedule of care for HIV-infected adults who are well-controlled on ART. Prior guidelines recommended routine monitoring of viral load and CD4 cell counts every 3-4 months [2]. The 2013 guidelines, however, recognize that patients with long-term suppression of viral load for more than 2-3 years do not typically require such frequent monitoring. Rather, in patients whose clinical and immunologic status are stable, the frequency of viral load and CD4 count determinations can be lengthened to every 6-12 months [1]. Similarly, the Department of Health and Human Services (DHHS) guidelines for the use of antiretroviral agents in HIV1 infected adults and adolescents propose monitoring CD4 cell counts every 6-12 months in patients on suppressive ART regimens whose CD4 cell count have increased well above the threshold for developing most opportunistic infections [3]. Viral load monitoring can be extended to 6-month intervals in adherent patients with a suppressed viral load and stable immunologic status for 2-3 years.

Due to the increased prevalence of diabetes in the HIV-infected population, a fasting glucose and/or hemoglobin $\mathrm{AlC}$ (HbA1C) is recommended to screen for glucose intolerance and diabetes [4]. The 2013 HIV primary care guidelines acknowledge the increasing use of $\mathrm{HbAlC}$ in the primary care setting, with the diagnosis of diabetes mellitus equating to a $\mathrm{HbAlC}$ value of $6.5 \%$ as defined by the American Diabetes Association [5]. However, the 2013 HIV primary care guidelines suggest a lower HbA1C threshold of $5.8 \%$ as this cut off has been associated with better sensitivity and specificity for patients on ART [6]. In the general population, asymptomatic screening for diabetes should be considered in adults of any age who are overweight or obese and have additional risk factors for diabetes. In those without risk factors, screening for diabetes should begin at age 45 [5]. The 2013 HIV primary care guidelines state that fasting glucose and/or HbA1C should be checked every 6-12 months in all patients with HIV [1]. Consideration for testing should occur prior to and 1-3 months after starting or modifying ART. Finally, HbA1C should be performed at least every 6 months in patients with controlleddiabetes mellitus and more frequently in patients not meeting treatment goals.

Similar to diabetes, dyslipdemia has been associated with HIV infection, ART, and traditional risk factors. For these reasons, the

*Corresponding author: Jason F. Okulicz, Department of Medicine, Division of Internal Medicine and Infectious Disease Service, San Antonio Military Medical Center, Brooke Army Medical Center, 3551 Roger Brooke Drive, Fort Sam Houston, TX 78234-6200, USA, Tel: 210-916-5554; Fax: 210-916-5900; E-mail: jason.f.okulicz.mil@mail.mil

Received December 20, 2013; Accepted December 23, 2013; Published December 28, 2013

Citation: Hannah WN, Okulicz JF (2013) Contemporary Recommendations for Primary Care Management of Patients with HIV Infection. J AIDS Clin Res 4: e113. doi:10.4172/2155-6113.1000e113

Copyright: (c) 2013 Hannah WN, et al. This is an open-access article distributed under the terms of the Creative Commons Attribution License, which permits unrestricted use, distribution, and reproduction in any medium, provided the original author and source are credited. 
Citation: Hannah WN, Okulicz JF (2013) Contemporary Recommendations for Primary Care Management of Patients with HIV Infection. J AIDS Clin Res 4: e113. doi:10.4172/2155-6113.1000e113

Page 2 of 3

\begin{tabular}{|c|c|c|}
\hline Test or Intervention & 2013 IDSA Guidelines & 2009 IDSA Guidelines \\
\hline Viral load & $\begin{array}{l}\text { Perform every } 3-4 \text { months; perform every } 6-12 \text { months if } \\
\text { clinically and immunologically stable for } 2-3 \text { years }\end{array}$ & Perform every 3-4 months \\
\hline CD4 cell count & $\begin{array}{l}\text { Perform every 3-4 months; perform every } 6-12 \text { months if } \\
\text { clinically and immunologically stable for } 2-3 \text { years }\end{array}$ & Perform every 3-4 months \\
\hline Fasting glucose and/or $\mathrm{HbA} 1 \mathrm{C}$ & $\begin{array}{l}\text { Perform every } 6-12 \text { months in all patients; consider } \mathrm{HbA} 1 \mathrm{C} \\
5.8 \% \text { as cutoff for diabetes mellitus }\end{array}$ & Perform fasting glucose every 6 months \\
\hline Fasting lipid profile & No change from 2009 recommendations & $\begin{array}{l}\text { Perform every } 6-12 \text { months; consider performing } 1-3 \text { months after } \\
\text { starting or modifying treatment; follow NCEP guidelines }{ }^{*}\end{array}$ \\
\hline Bone Densitometry & $\begin{array}{l}\text { Perform baseline exam in postmenopausal women and men } \\
\text { age } \geq 50 \text {; periodic monitoring thereafter }\end{array}$ & $\begin{array}{l}\text { Perform baseline exam in postmenopausal women aged } \geq 65 \text { years } \\
\text { and in younger postmenopausal women with } 1 \text { or more other risk } \\
\text { factor(s) for premature bone loss; consider in persons aged } \geq 50 \\
\text { years, especially if they have } \geq 1 \text { risk factor(s) for premature bone } \\
\text { loss; periodic monitoring thereafter }\end{array}$ \\
\hline Pneumococcal vaccine & $\begin{array}{l}\text { Patients should receive a dose of PCV13 (Prevnar 13), } \\
\text { followed by a dose of PPV23 (Pneumovax) at least } 8 \text { weeks } \\
\text { later. If previously vaccinated with PPV23, give PCV13 at } \\
\text { least } 1 \text { year after PPV23; administer to patients with CD4 cell } \\
\text { count } \geq 200 \text { cells/ } \mu \text { L. A second PPV23 dose is recommended } \\
5 \text { years after the first PPV23 dose }\end{array}$ & $\begin{array}{l}\text { Patients should receive PPV23; administer to patients with CD4 } \\
\text { cell count }>200 \text { cells/uL; consider booster dose } 5 \text { years after initial } \\
\text { immunization }\end{array}$ \\
\hline HPV vaccine & Indicated for females age 9-26 and males age 9-26 & $\begin{array}{l}\text { Indicated for females aged 9-26 years but may consider in other } \\
\text { groups }\end{array}$ \\
\hline Anal Pap test & $\begin{array}{l}\text { Anal Pap test should be performed in MSM, women with a } \\
\text { history of receptive anal intercourse or abnormal cervical Pap } \\
\text { test results, and all HIV-infected persons with genital warts }\end{array}$ & Consider if indicated \\
\hline Trichomoniasis screening & $\begin{array}{l}\text { Perform annually in all women; repeat testing } 3 \text { months later } \\
\text { if positive }\end{array}$ & $\begin{array}{l}\text { Screen at initial visit followed by periodic screening in high-risk } \\
\text { groups }\end{array}$ \\
\hline Gonorrhea and chlamydia screening & $\begin{array}{l}\text { Perform annually in patients at risk for STDs; more frequent } \\
\text { testing may be indicated in patients at high risk for STDs; } \\
\text { repeat testing } 3 \text { months later if positive }\end{array}$ & $\begin{array}{l}\text { Perform annually in patients at risk for STDs;more frequent testing } \\
\text { may be indicated in patients at high risk for STDs }\end{array}$ \\
\hline
\end{tabular}

Table 1: Summary of Major Changes in the 2013 IDSA HIV Primary Care Guidelines.

*New American College of Cardiology/American Heart Associationlipid management guidelines were published in November 2013 replacing NCEP guidelines.

DHHS guidelines and both the 2009 and 2013 HIV primary care guidelines recommend obtaining a fasting lipid profile upon initiation of care [1-3]. These guidelines also recommend evaluation of lipids at ART initiation and between 2 weeks and 3 months after starting ART. Patients with abnormal lipids should be managed according to the National Cholesterol Education Program (NCEP) guidelines [7]. Within the 2013 HIV primary care guidelines, dyslipidemia is addressed under the topic of metabolic comorbidities associated with HIV and ART. In addition, the 2013 guidelines include a detailed table on drug interactions between statins, protease inhibitors (PIs), and non-nucleoside reverse transcriptase inhibitors (NNRTIs). Since the publication of the 2013 IDSA update, new lipid management guidelines werereleased by the American College of Cardiology/American Heart Association in November 2013 which emphasize global risk assessment rather than treat-to-cholesterol targets [8]. It remains to be seen how widely these new cholesterol treatment recommendations will be adopted in clinical practice. Lastly, the authors acknowledge that randomized controlled trials for lipid management in HIV-infected patients are lacking and further studies are needed in order to develop specific recommendations for patients with HIV.

HIV infection and use of ART increase the risk of premature bone loss thereby exacerbating the risk of osteopenia and osteoporosis, and there is some evidence to suggest that HIV-infected women develop premature physiologic menopause [1]. For these reasons, the 2013 HIV primary care guidelines recommend baseline bone densitometry (DXA) screening for osteoporosis in HIV-infected postmenopausal women and men $\geq 50$ years [1]. The 2009 IDSA guidelines for HIV management did not recommend routine osteoporosis screening. Rather, screening was considered for patients older than 50 years and those with more than 1 risk factor for premature bone loss [2]. The National Osteoporosis Foundation (NOF) considers HIV to be a disease known to cause or contribute to osteoporosis [9]. Thus, the NOF clinical practice guidelines for osteoporosis are consistent with the $2013 \mathrm{HIV}$ primary care guidelines.Similar to the prior 2009 guidelines, the 2013 primary care guidelines also recommend counseling patients about risk factors of osteopenia and osteoporosis, such as cigarette smoking and excessive alcohol use, and the importance of regular exercise and adequate intake of calcium and vitamin $\mathrm{D}[1,2]$.

Both the 2009 and 2013 HIV primary care management guidelines give strong recommendations for routine immunizations in HIVinfected adults for pneumococcal infection, influenza, varicella, and hepatitis $A$ and $B[1,2]$. Response to any vaccine has been shown to be more robust in patients on ART with higher CD4 cell counts which further emphasizes the importance of ART in HIV-infected persons $[1,10]$. With the addition of the PCV13 (Prevnar 13) vaccine, the 2013 HIV guidelines have updated recommendations for the pneumococcal vaccination schedule. HIV-infected adults should be routinely vaccinated with one dose of PCV13, followed by a dose of PPV23 (Pneumovax) at least 8 weeks later. Patients previously vaccinated with PPV23 should receive PCV13 at least 1 year after PPV23. Human papilloma virus (HPV) vaccination is now recommended in all males aged 9-21 and males aged 22-26 if not previously vaccinated [1]. Prior to this recommendation for men, the 2009 guidelines suggested HPV vaccination only be considered in perinatally HIV-infected adolescents who are not sexually active and young adults who may be at additional risk of acquiring HPV [2].

HIV infected men and women with HPV infection are at increased risk for anal dysplasia and cancer, particularly men who have sex with men (MSM). In fact, anal cancer is the fourth most common cause of cancer in patients living with HIV or AIDS [11]. The 2013 HIV primary care guidelines have new recommendations for anal cytologic screening (anal Pap test), which should be performed in MSM, women 
with a history of receptive anal intercourse or abnormal cervical Pap test results, and all HIV-infected persons with genital warts [1]. This recommendation is based on moderate quality evidence and remains somewhat controversial. Anal Pap tests were not routinely recommended in the 2009 HIV primary care guidelines, likely due to the lack of data showing mortality benefit with this screening strategy. Anal cytology is a reasonable predictor of anal intraepithelial neoplasia (AIN), but there is poor correlation between cytology and histologic grade [11]. Unfortunately, no randomized controlled trials have documented the value of AIN screening to date. Thus, the recommendation to perform anal Pap tests in the 2013 HIV guidelines relies mostly on the histologic similarity between the cervix and the anus and the significant benefits of cervical cytology screening in reducing the incidence of cervical cancer. In those individuals with abnormal results, high-resolution anoscopy should be performed with biopsy of abnormal areas and appropriate therapy based on biopsy results [12]. Recommendations for cervical cancer screening in women are unchanged, with cervical Pap testing indicated upon initiation of care, repeated at 6 months, then annually thereafter if results are normal $[1,2]$

Recognizing that many sexually transmitted diseases (STDs) are asymptomatic, the 2013 IDSA update on primary care management of HIV further emphasizes theimportanceofSTD screening. In an enhanced section on STDs, the 2013 guidelines have new recommendations for trichomoniasis screening in women and increased frequency of screening for gonorrhea and chlamydial infections in both men and women. Previously, screening for trichomoniasis was recommended at the initial visit followed by periodic screening in high-risk groups [2]. Current guidelines now suggest annual screening for trichomoniasis in women with repeat testing in 3 months for those with positive tests due to high short-term rates of re-infection. Similarly, both gonorrhea and chlamydia should be assessed initially then followed with annual screening in men and women at risk for infection. For those individuals testing positive, repeat testing is now recommended in 3 months to document eradication [1].

HIV-infected individuals in developed countries can now enjoy a near normal life expectancy due to the many advances in the field of HIV medicine. With increasing life span, HIV has evolved from a disease with limited treatment options to a chronic condition that can be successfully managed with ART. As patients with HIV advance in age, anincreased focus on comorbid conditionssuch as diabetes, hyperlipidemia, and osteoporosis is essential. A combination of effective ART, routine vaccination, and preventive care is necessary to improve long-term outcomes in HIV-infected patients. As reflected by the 2013 IDSA update on primary care guidelines for the management of patients infected with HIV, new and updated recommendations emphasize the importanceof primary care in the treatment of HIVinfected individuals.

\section{References}

1. Aberg JA, Gallant JE, Ghanem KG, Emmanuel P, Zingman BS, et al. (2013) Primary Care Guidelines for the Management of Persons Infected With HIV: 2013 Update by the HIV Medicine Association of the Infectious Diseases Society of America. Clin Infect Dis 58: e1-e34.

2. Aberg JA, Kaplan JE, Libman H, Emmanuel P, Anderson JR, et al. (2009) Primary care guidelines for the management of persons infected with human immunodeficiency virus: 2009 update by the HIV medicine Association of the Infectious Diseases Society of America. Clin Infect Dis 49: 651-681.

3. AIDS Info (2013) Guidelines for the use of antiretroviral agents in HIV-1infected adults and adolescents. Developed by the HHS Panel on Antiretrovira Guidelines for Adults and Adolescents - A Working Group of the Office of AIDS Research Advisory Council (OARAC)

4. Samaras K (2009) Prevalence and pathogenesis of diabetes mellitus in HIV-1 infection treated with combined antiretroviral therapy. J Acquir Immune Defic Syndr 50: 499-505.

5. [No authors listed] (2013) Executive summary: Standards of medical care in diabetes--2013. Diabetes Care 36 Suppl 1: S4-10.

6. Eckhardt BJ, Holzman RS, Kwan CK, Baghdadi J, Aberg JA (2012) Glycated Hemoglobin $A(1 c)$ as screening for diabetes mellitus in HIV-infected individuals. AIDS Patient Care STDS 26: 197-201.

7. Expert Panel on Detection, Evaluation, and Treatment of High Blood Cholesterol in Adults (2001) Executive Summary of The Third Report of The National Cholesterol Education Program (NCEP) Expert Panel on Detection, Evaluation, And Treatment of High Blood Cholesterol In Adults (Adult Treatment Panel III). JAMA 285: 2486-2497.

8. Stone NJ, Robinson J, Lichtenstein AH, Bairey Merz CN, Lloyd-Jones DM, et al (2013) ACC/AHA Guideline on the Treatment of Blood Cholesterol to Reduce Atherosclerotic Cardiovascular Risk in Adults: A Report of the American College of Cardiology/American Heart Association Task Force on Practice Guidelines. Circulation: 1-85.

9. National Osteoporosis Foundation (2013) Clinician's Guide to Prevention and Treatment of Osteoporosis.

10. Landrum ML, Fieberg AM, Chun HM, Crum-Cianflone NF, Marconi VC, et al. (2010) The effect of human immunodeficiency virus on hepatitis $B$ virus serologic status in co-infected adults. PLoS One 5: e8687.

11. Mani D, Aboulafia DM (2013) Screening guidelines for non-AIDS defining cancers in HIV-infected individuals. Curr Opin Oncol 25: 518-525.

12. US Department of Veteran Affairs (2011) Anal dysplasia. Primary Care of Veterans with HIV, Organ Systems and Metabolic. 